\title{
Metodologia de \\ projetos e atividades \\ educomunicativas na \\ formação do professor
}

Suyanne Tolentino Souza

Professora titular da Pontifícia Universidade Católica do Paraná - Escola de Comunicação e Artes.

E-mail: suyanne.souza@pucpr.br

Resumo: Este estudo tem por objetivo avaliar a contribuição de um projeto de práticas educomunicativas, inseridas nos campos da comunicação e educação, no processo de formação do docente. Auxiliando estudantes de jornalismo em seu contato com a realidade social, nesta pesquisa de caráter qualitativo e método pesquisa-formação, realizou-se atualização curricular a partir da implantação de uma nova disciplina, modelada segundo a metodologia de projetos, favorecendo a relação orgânica entre atividades de pesquisa e ensino. Dos resultados encontrados é possível afirmar que, na perspectiva do desenvolvimento de novas metodologias de ensino, o planejamento e a ação que envolve professores, estudantes e comunidade contribuem para a prática educativa que incentiva o compromisso com a transformação social.

Palavras-chave: educomunicação; metodologia de projetos; pesquisa-formação, graduação; jornalismo.
Abstract: This study aims to evaluate the contribution of a project of educommunication practices inserted in the fields of communication and education, for the teacher training process. By helping journalism students in their contact with the social reality, in this qualitative study and research-training method, a curricular update was performed with the implementation of a new discipline, modeled according to the project methodology, favoring an organic relationship between research and teaching activities. Based on the results of this study, and in the perspective of the development of new teaching methodologies, planning and action involving teachers, students, and community contribute to educational practices that encourage the commitment to social transformation.

Keywords: educommunication; project methodology; research-training; graduation; journalism. 
1. CITELLI, Adilson O. COSTA, Maria Cristina C. (orgs.). Educomunicação: construindo uma nova área de conhecimento. São Paulo: Paulinas, 2011. p. 26

2. FREIRE, Paulo. Extensão ou comunicação? São Paulo: Paz e Terra, 1983.

3. FREIRE, Paulo. Pedagogia da autonomia: saberes necessários à prática educativa. São Paulo: Paz e Terra, 2003

4. SOARES, Ismar de Oliveira. Educomunicação: conceito, o profissional, a aplicação. São Paulo: Paulinas, 2011.

5. DEMO, Pedro. Desafios modernos da educação. Petrópolis: Vozes, 1995.

6. BEHRENS, Marilda Aparecida. Projetos de aprendizagem colaborativa num paradigma emergente. In: MORAN José Manuel; MASETTO, Marcos Tarciso; BEHRENS, Marilda Aparecida. Novas tecnologias e mediação pedagógica. Campinas:

Papirus, 2000

7. BEHRENS, Marilda Aparecida. Paradigma da complexidade. Petrópolis: Vozes, 2008

8. MORAN, José Manuel. A educação que desejamos: novos desafios e como chegar lá. Campinas: Papirus, 2007

9. MORIN, Edgar. Os sete saberes necessários à educação do futuro. São Paulo: Cortez; Brasília, DF: Unesco, 2011

10. SANTOS, Edmea Pesquisa-formação na cibercultura. Santo Tirso: Whitebooks, 2014. p. 24.

\section{INTRODUÇÃO}

Comunicação e educação são ciências que, quando articuladas, inauguram um espaço interdiscursivo constituinte de um novo campo de saber. A aproximação dessas áreas apresenta novas possibilidades de práticas circunscritas no âmbito da educomunicação, que busca "pensar, pesquisar, trabalhar a educação

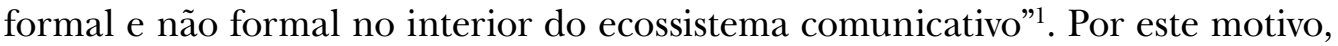
foram revisitados, aqui, os conceitos de comunicação educativa e educomunicação baseados em Freire ${ }^{2,3}$ e Soares ${ }^{4}$. Refletiu-se, ainda, sobre novas metodologias que possam atender às necessidades da realidade atual, baseadas em Demo $^{5}$, Behrens $^{6,7}$, Moran $^{8}$ e Morin ${ }^{9}$.

No intuito de trabalhar os desdobramentos das atividades educomunicativas e sua importância na prática do docente, esta pesquisa propôs o desenvolvimento de uma nova disciplina no curso de jornalismo de uma faculdade particular brasileira. Por meio dessa disciplina, denominada "Mídia e Educação", intencionou-se avaliar a influência do uso da metodologia de projetos na formação do docente. Por essa razão, durante o desenvolvimento acompanhou-se o processo de ensino-aprendizagem dos estudantes a partir dos direcionamentos, da mediação, do saber e, especialmente, da didática metodológica do professor. Entende-se, então, a necessidade de os professores estarem atentos às demandas da sociedade para melhor preparar seus estudantes no seu manejo e atendimento. A implantação da disciplina Mídia e Educação, nesse contexto, se apresenta como uma atualização curricular que permite elaborar metodologias inovadoras, adaptando o processo de ensino-aprendizagem a cada nova situação.

O objeto deste estudo, portanto, é a relação entre a formação do docente e o exercício da educomunicação no processo de ensino-aprendizagem. Entende-se que a metodologia de projetos não visa atender apenas a realidade específica de seu público-alvo, mas também auxiliar na formação de quem a desenvolve, uma vez que aproxima teoria e prática dentro de uma realidade específica. Por essa razão, considerando que a interação entre o docente e os estudantes ocorreu sob a mediação da aprendizagem, este estudo, que teve apoio do Programa Finep de Inovação, configurou-se como uma pesquisa-formação.

A pesquisa-formação como método de intervenção caracteriza-se pelo processo de ensinar e pesquisar a partir do compartilhamento de diferentes narrativas, nas quais se incorporam aspectos comunicacionais e pedagógicos. Esse método envolve um grupo de sujeitos que "aprende enquanto ensina e pesquisa, e pesquisa e ensina enquanto aprende" 10 .

Sobre os resultados encontrados, é possível afirmar que, na perspectiva do desenvolvimento de novas metodologias de ensino, o planejamento e a ação que envolvem professores, estudantes e comunidade ampliam horizontes e contribuem para uma prática educativa emancipadora, possibilitando um processo de transformação social. 


\section{COMUNICAÇÃO E EDUCAÇÃO}

Comunicação e educação são ciências que têm seus campos teóricos aproximados, principalmente pelo processo de midiatização no contexto escolar. A inter-relação entre essas ciências ocorre num espectro maior, que envolve o seu diálogo e se materializa por ações educomunicativas.

Para Freire ${ }^{11}$, a Educação se fundamenta num universo de comunicação, e não numa simples transferência de saber; é, portanto, um encontro de interlocutores na busca de significados. Para Moran ${ }^{12}$, a educação é fundamentalmente um processo de comunicação e troca de informações entre pessoas. Essencialmente, comunicação e educação convergem na interação humana e articulam a temática da cidadania comunicativa ${ }^{13}$.

Refletir a respeito da aproximação desses campos científicos e afirmar que ambos ocupam territórios comuns significa aproveitar ao máximo sua potencialidade na interação do fazer integrado que caracteriza a educomunicação como uma nova área interdisciplinar. Segundo Soares ${ }^{14}$, a educomunicação caracteriza-se por criar e desenvolver "ecossistemas comunicativos", qualificados como abertos e criativos, que se dão em "áreas de intervenção" do novo campo da comunicação e educação.

Ainda, a educomunicação permite a implementação de políticas de comunicação educativa de modo a desenvolver o acesso democrático à produção e difusão da informação, identificar como o mundo pode ser editado nos meios de comunicação, facilitar o processo de ensino-aprendizagem e promover a expressão comunicativa dos membros da comunidade educativa ${ }^{15}$.

O contexto e a inter-relação que aproximam comunicação e educação também estimulam a inserção de novas disciplinas e conteúdos na formação que envolve essas áreas. Embora o conceito de disciplina ainda seja muito segmentado, na perspectiva interdisciplinar há uma valorização do saber a partir da relação entre os múltiplos instrumentos de conhecimento. Aprender a relacionar os conteúdos dessas ciências de maneira conjunta ou integrada potencializa suas capacidades explicativas, permitindo melhor perspectiva de atuação docente através de postura crítica e inovadora. Esse fato, inclusive, propicia o surgimento da reorganização disciplinar e da constituição de novos objetos de estudo e saber, incentivando novas realidades no domínio das ciências sociais.

Pensar o futuro profissional do docente, envolvendo conceitos da comunicação educativa e educomunicação, é um passo importante para a adaptação a um mercado cada vez mais competitivo e inovador. A educomunicação viabilizou essa interação a partir da práxis para promover mudanças paradigmáticas no convívio do cidadão, afinal comunicação e educação incentivam o exercício da cidadania ao enriquecer a interpretação de seus interlocutores acerca da realidade vivida.

Por meio da comunicação é possível traçar alternativas e aproximar a educação da realidade na qual está inserida. Convém, nesse contexto, afirmar que neste estudo considerou-se não apenas a educação formal, mas também a informal, presente no cotidiano.

11. FREIRE, op. cit., 1983.

12. MORAN, op. cit.

13. KAPLÚN, Mario. Comunicación entre grupos: el método del Cassete-Foro. Buenos Aires: Humanitas, 1988.

14. SOARES, op. cit. 15. SOARES, op. cit. 
A aproximação do docente no fazer da educomunicação exige um novo pensar sobre as metodologias de ensino para a elaboração de estratégias de intervenção que propiciem aos estudantes uma maior capacidade de respostas em uma realidade complexa.

\section{A INTERVENÇÃO POR MEIO DA EDUCOMUNICAÇÃO}

Os novos processos e práticas jornalísticas no âmbito da convergência de mídias resultaram em questionamentos sobre a importância do jornalismo e do jornalista no exercício da cidadania. Isso, que é a primeira função social do jornalista, fica obscurecido diante das tecnologias de comunicação, que trazem mudanças significativas para o exercício da profissão, além das próprias exigências do mercado.

Por esse motivo, elegeu-se como objeto de pesquisa observar a influência da educomunicação no processo formativo do docente ao implantar uma nova disciplina para os estudantes de jornalismo de uma universidade particular brasileira, a partir de um ajuste no currículo do curso. Observou-se a necessidade de redefinir os elementos do currículo em questão para voltar-se à essência da profissão e possibilitar alternativas para quem atua na área. Para enfrentar os desafios da sociedade global e complexa, providenciou-se a mudança na formação desses estudantes de modo a torná-los capazes de responder aos problemas que uma vida comprometida com a melhoria da sociedade e de si mesmos lhes apresentará16.

De acordo com Morin $^{17}$, a hiperespecialização, ou seja, a especialização que se fecha sobre si mesma sem permitir a integração na problemática global, impede tanto a percepção do todo quanto do essencial, prejudicando o tratamento correto de problemas particulares que só podem ser propostos e pensados em seus contextos. $\mathrm{O}$ autor pontua a importância da união dos saberes para sua contextualização, afirmando que o recorte das disciplinas impossibilita apreender "o que está tecido junto, segundo o sentido original do termo, o complexo"18.

No intuito de trabalhar os desdobramentos práticos das atividades relacionadas aos campos da comunicação e da educação, e de atualizar o currículo do curso de jornalismo, foi inserida na grade curricular a disciplina Mídia e Educação. Para o desenho dessa disciplina partiu-se do princípio de que o jornalista tem um importante papel no que se refere à educomunicação, sendo necessário fortalecer sua capacidade de responder às necessidades do contexto, caracterizado pela inserção de mídias em diferentes situações e pela comunicação como pontos-chave das relações.

Com a proposta de trazer para o currículo uma dimensão social contemporânea e articulada, seguindo as Diretrizes Curriculares Nacionais para o curso de graduação em jornalismo ${ }^{19}$, especificamente o art. $5^{\mathrm{o}}$, sobre o concluinte do curso estar apto a "atuar como produtor intelectual e agente da cidadania", optou-se por inserir na referida disciplina os temas transversais. 
Ao discutir questões relevantes relacionadas ao poder da comunicação como emancipadora, a perspectiva dos temas transversais nessa disciplina contribui para a seleção e organização de conteúdos da realidade global. Segundo o Ministério da Educação, temas transversais são aqueles voltados "para a compreensão da realidade social e dos direitos e responsabilidades em relação à vida pessoal e coletiva e a afirmação do princípio da participação política” ${ }^{20}$. Desta forma, devem ser trabalhados nas disciplinas já existentes.

Entende-se que os temas transversais referentes à cidadania no âmbito da comunicação para e com a comunidade contribuem para questões urgentes no cotidiano. Optou-se, portanto, por trabalhar com os estudantes e a comunidade, após pesquisa de campo, temas relacionados à cidadania, em seus aspectos éticos, à saúde e ao meio ambiente.

Considerando que o exercício da cidadania não se aprende limitando-se à sala de aula, a disciplina Mídia e Educação envolveu especialmente a intervenção na comunidade. Buscou-se estabelecer metodologias de ensino mais apropriadas para promover aprendizagens significativas em diferentes circunstâncias. Assim, aproximou-se o exercício do jornalismo das práticas dos agentes culturais, educadores e comunicadores no exercício de ações educomunicativas.

\section{APRENDIZAGEM ATIVA POR MEIO DA METODOLOGIA DE PROJETOS}

Os processos de ensino e aprendizagem incidem em seu caráter singular e pessoal, "de maneira que o problema de ensinar não se situa basicamente nos conteúdos, mas em como se aprende e, consequentemente, em como se deve ensinar para que essas aprendizagens sejam produzidas" ${ }^{21}$.

A proposta do ensino com pesquisa, que possibilita a busca, criação e produção do conhecimento, é uma metodologia que já vem sendo desenvolvida para favorecer a aprendizagem ativa, incentivando maior participação do estudante como investigador. Para Kozanitis (informação verbal) ${ }^{22}$, trata-se de uma forma de engajar o estudante diretamente no raciocínio e na resolução de problemas através da aprendizagem ativa ou experimental.

Nesse sentido, o ensino não está centrado no professor e o conhecimento não é apenas acumulado ou armazenado, superando a simples memorização. A escola, portanto, não é o único lugar onde se realiza a educação. O contexto atual exige que o professor seja um facilitador da aprendizagem, atuando como um mediador ${ }^{23}$ e respeitando o caráter individual do estudante. $\mathrm{O}$ ambiente escolar se amplia, transcende os muros das instituições educacionais, o que exige processos metodológicos que permitam "aprender a aprender" ${ }^{24}$.

Para Behrens ${ }^{25}$, a metodologia de projetos baseada no ensino com pesquisa possibilita uma aprendizagem pluralista, que permite articulações diferenciadas de cada estudante envolvido no processo. Favorece, nesse sentido, situações de aprendizagem significativa nas quais o estudante passa a ser o protagonista.
20. BRASIL. Ministério da Educação. Secretaria de Educação Fundamental. Parâmetros Curriculares Nacionais: terceiro e quarto ciclos - apresentação dos temas transversais. Brasília, DF: MEC; SEF, 1998. p. 17. 21. ZABALA, op. cit., p. 22.

22. Informação fornecida por Anastassis Kozanitis na palestra "Estratégias e métodos de ensino para a aprendizagem ativa: ajudando estudantes a desenvolver habilidades e raciocínio", realizada na PUC-PR, Curitiba, 26 jul. 2016.

23. SOUZA, Suyanne Tolentino. Ensino-aprendizagem na cibercultura: a mediação pedagógica na modalidade vídeo na educação superior. 2014. 291 f. Dissertação (Doutorado) - Pontifícia Universidade Católica do Paraná, Curitiba, 2014. Disponível em: <http://www.biblioteca.pucpr.br/tede/tde_busca/arquivo.php?codArquivo $=2960 \mathrm{P}$. Acesso em: 1 jun. 2017.

24. DEMO, op. cit. 25. BEHRENS, op. cit., 2000. 
Trata-se da superação de um modelo em que o conteúdo era apresentado de modo a ser decorado e repetido para, então, possibilitar ao estudante a reflexão crítica e o desenvolvimento do pensamento autônomo.

Para propor a metodologia de projetos no processo de ensino-aprendizagem convém, também, considerar a perspectiva de Morin ${ }^{26}$ sobre a necessidade de situar tudo no contexto e no complexo planetário. Somente assim pode-se articular e organizar os conhecimentos para a reforma do pensamento, que é "paradigmática e não programática", na qual as realidades ou os problemas são cada vez mais multidimensionais, transnacionais, globais e planetários. Portanto Morin afirma que, para tornar o conhecimento pertinente, a educação deverá evidenciar: o contexto, o global, o multidimensional e o complexo. O contexto situa as informações e os dados para que adquiram sentido; o global é mais do que o contexto, envolvendo o todo e suas partes; o multidimensional envolve unidades complexas do ser humano e da sociedade; e o complexo se refere aos elementos inseparáveis constitutivos do todo.

\section{DESCRIÇÃO DA PESQUISA}

Este estudo foi desenvolvido através do método da pesquisa-formação, voltando-se à relação teórico-prática do professor no seu exercício. Trata-se de um tipo de pesquisa que possibilita a participação efetiva do professor nas atividades realizadas e apresenta flexibilidade em relação ao conteúdo investigado. A prioridade é a formação do professor, e não a coleta de dados. Assim é possível produzir, ampliar e aperfeiçoar saberes sobre as práticas pedagógicas mediante a investigação do docente em seu próprio espaço de trabalho.

É nessa perspectiva de prática reflexiva, crítica e transformadora que se apresenta a implantação da disciplina Mídia e Educação. No contexto de aprendizagem, por meio dessa atualização curricular, pôde-se utilizar diferentes dispositivos que se configuram como espaços formativos de pesquisa e exercício pedagógico para produção de dados: observação participante, memórias de pesquisa e da prática profissional.

Os ambientes de pesquisa foram a sala de aula e as comunidades atendidas, envolvendo a formação de 22 estudantes regularmente matriculados no primeiro semestre de 2017. A implantação da disciplina Mídia e Educação se deu no segundo semestre de 2016, no curso de jornalismo de uma universidade particular brasileira. A constituição da disciplina estava ancorada no "aprender a aprender”27, especialmente na proposição do ensino com pesquisa por meio da metodologia de projetos. Segundo Behrens ${ }^{28}$, projeto pode significar tanto o objeto que se quer produzir quanto o método que o caracteriza.

Tanto a metodologia adotada no desenvolvimento da disciplina quanto o

26. MORIN, op. cit., p. 33 27. DEMO, op. cit. 28. BEHRENS, op. cit., 2008 . produto resultante dela, desenvolvido pelos estudantes com as comunidades nas quais se realizou a mediação, denomina-se nesta pesquisa como "projeto". O Quadro 1 apresenta as duas etapas que a proposta-ação da disciplina envolve. 


\section{Quadro 1: Dimensão da implantação da disciplina em um contexto globalizador}

\begin{tabular}{|c|c|}
\hline \multirow{2}{*}{$\begin{array}{c}\text { Proposta-ação da disciplina e intervenção } \\
\text { na comunidade }\end{array}$} & $\begin{array}{c}\text { Implantação da metodologia de projetos em } \\
\text { atividades educomunicativas. }\end{array}$ \\
\cline { 2 - 2 } & $\begin{array}{c}\text { Pertinência do conhecimento no complexo } \\
\text { planetário }{ }^{29} \text {. }\end{array}$ \\
\hline
\end{tabular}

Fonte: Elaborado pela autora.

Os procedimentos metodológicos de investigação foram estabelecidos nas categorias apresentadas nos Quadros 2 e 3.

\section{Quadro 2: Proposta-ação da disciplina e intervenção na comunidade}

\begin{tabular}{|c|c|}
\hline & Tema \\
\cline { 2 - 2 } $\begin{array}{c}\text { Proposta-ação da disciplina - } \\
\text { implantação da metodologia de } \\
\text { projetos }\end{array}$ & Problematização \\
\cline { 2 - 2 } & Desenvolvimento \\
\cline { 2 - 2 } & Aplicação \\
\cline { 2 - 2 } & Avaliação \\
\hline
\end{tabular}

\section{Quadro 3: Parâmetros de análise da proposta-ação da disciplina}

\begin{tabular}{|c|c|}
\hline \multirow{4}{*}{$\begin{array}{c}\text { Proposta-ação da disciplina - complexo } \\
\text { planetário }\end{array}$} & O contexto \\
\cline { 2 - 2 } & O global \\
\cline { 2 - 2 } & O multidimensional \\
\cline { 2 - 2 } & O complexo \\
\hline
\end{tabular}

Fonte: Adaptação dos princípios do conhecimento pertinente de Morin ${ }^{32}$.

\section{ANÁLISE E DISCUSSÃO DOS DADOS}

A disciplina Mídia e Educação foi desenvolvida de forma teórico-prática para atender à necessidade de mercado e desenvolver o pensamento crítico-reflexivo do futuro jornalista em contexto global. O objetivo era mostrar aos estudantes que teoria e prática são inseparáveis, enquanto a experiência enriquecia a formação do professor.

Para tanto, a disciplina foi implantada de modo que a metodologia desenvolvida pelo professor em sala de aula fosse também utilizada pelos estudantes quando realizassem o projeto na comunidade. A investigação seguiu o contrato pedagógico que previa análise e discussão crítica sobre a comunicação e utilização de mídias como instrumentos educativos e de contribuição para a comunidade. 
Foram também utilizadas metodologias ativas por meio do desenvolvimento de projetos. A disciplina foi pautada em dois pilares fundamentais: comunicação não violenta e pedagogia do afeto.

A comunicação não violenta refere-se a um processo empático de entendimento que facilita a harmonização do todo, possibilitando a cooperação e o apoio mútuo, valorizando os sentimentos e a opinião do outro ${ }^{33}$. A pedagogia do afeto trata do desenvolvimento do estudante como pessoa humana, envolvendo o respeito à liberdade e o apreço à tolerância, inspirada nos princípios da livre escolha e nos ideais de solidariedade. Possui como objetivo o pleno desenvolvimento do estudante, seu preparo para o exercício da cidadania e sua qualificação para novas ocupações no mundo do trabalho.

\section{PROPOSTA-AÇÃO DA DISCIPLINA}

Buscou-se identificar os princípios do conhecimento pertinente e como estes foram articulados no decorrer da disciplina. Durante a implantação desta, por meio da proposição da metodologia de projetos, as sugestões de fases propostas por Behrens ${ }^{34}$ foram seguidas, com algumas adaptações (Quadro 4).

\section{Quadro 4: Etapas da metodologia de projetos de Behrens ${ }^{35}$, adaptadas para aplicação educomunicativa}

33. ROSEMBERG, Marshall B. Comunicação não violenta: técnicas para aprimorar relacionamentos pessoais e profissionais. São Paulo: Ágora, 2006.

34. BEHRENS, op. cit., 2008 . 35. Ibid.

\begin{tabular}{|l|l|l|}
\hline $\begin{array}{l}\text { Etapa da metodologia } \\
\text { de projetos }\end{array}$ & \multicolumn{1}{|c|}{ Descrição } & $\begin{array}{l}\text { Atividades educomunicativas } \\
\text { propostas }\end{array}$ \\
\hline Tema & $\begin{array}{l}\text { Apresentação e discussão do } \\
\text { projeto com questões norteadoras } \\
\text { para o desenvolvimento do tema. }\end{array}$ & $\begin{array}{l}\text { Apresentação e discussão do } \\
\text { projeto. } \\
\text { Projeto: "Atuação educomunicativa } \\
\text { comunitária". }\end{array}$ \\
\hline Problematização & $\begin{array}{l}\text { Definição da situação-problema e } \\
\text { do objetivo geral (onde se quer } \\
\text { chegar?). Explicação de como o } \\
\text { projeto será desenvolvido. }\end{array}$ & $\begin{array}{l}\text { Contextualização de temas } \\
\text { que envolvem a disciplina; } \\
\text { realização de aulas teóricas } \\
\text { e exploratórias por meio de } \\
\text { metodologias ativas. }\end{array}$ \\
\hline Desenvolvimento & $\begin{array}{l}\text { Busca de respostas por meio de } \\
\text { atividades propostas pelo professor } \\
\text { - individuais e coletivas. }\end{array}$ & $\begin{array}{l}\text { Pesquisa individual e produção } \\
\text { coletiva. } \\
\text { Planejamento das ações. }\end{array}$ \\
\hline Aplicação & $\begin{array}{l}\text { Execução do projeto em sua } \\
\text { realidade. }\end{array}$ & $\begin{array}{l}\text { Inserção na prática social. } \\
\text { Aplicação de atividades na } \\
\text { comunidade. Desenvolvimento } \\
\text { das açães planejadas. }\end{array}$ \\
\hline Avaliação & $\begin{array}{l}\text { Verificação da aprendizagem } \\
\text { adquirida - avaliação processual } \\
\text { por meio de acompanhamento e } \\
\text { desenvolvimento de portfólio. }\end{array}$ & $\begin{array}{l}\text { Apresentação do portfólio. } \\
\text { Produção de reportagens } \\
\text { individuais. Apresentação para } \\
\text { o grupo. }\end{array}$ \\
\hline
\end{tabular}

Fonte: Elaborado pela autora. 


\subsection{Etapa de apresentação e discussão do projeto}

Nessa primeira fase, a pesquisadora e orientadora dos projetos desenvolvidos apresentou com clareza a disciplina e seu contrato didático. Foram abordados: temas de estudo do semestre; descrição das atividades a serem desenvolvidas pelos estudantes antes, durante e depois dos encontros presenciais; procedimentos metodológicos e situações de aprendizagem; e processos avaliativos.

Para desenvolver a aprendizagem por meio da metodologia de projetos discutiu-se com os estudantes a forma como a disciplina estava planejada para que opinassem e reconstruíssem, se necessário, as fases propostas. Considerou-se importante aceitar a opinião dos estudantes em uma relação dialógica para o êxito na produção do conhecimento.

Nos primeiros encontros alguns questionamentos foram discutidos com os estudantes: qual a sua função social como jornalista? Como você pode contribuir para o local ou a sociedade onde mora? Qual legado você quer deixar enquanto comunicador?

Por meio dessas perguntas, feitas em uma carta-convite direcionada a cada estudante, estimulou-se sua participação na disciplina e a realização de mudanças. Enquanto comunicadores prestes a se formar, notou-se sua dificuldade para responder aos questionamentos mencionados. O projeto da disciplina foi intitulado "Atuação educomunicativa comunitária".

\subsection{Etapa de problematização}

Embora existisse uma pergunta inicial proposta pela professora, o objetivo era que vários outros questionamentos surgissem à medida que a disciplina fosse construída. Nessa etapa foram realizadas breves exposições teóricas e várias atividades exploratórias.

No primeiro bimestre foram ministradas algumas aulas expositivas dialogadas. Nessas atividades, adotou-se a sala de aula invertida como recurso para que os estudantes lessem textos de diferentes autores e enviassem para a professora seus questionamentos. Assim foram abordados os principais autores que pesquisaram sobre o campo dialógico da comunicação e da educação, de modo a instigar os estudantes a buscar mais informações para enriquecer o processo de construção do conhecimento.

\subsection{Etapa de desenvolvimento}

Embora descritas de forma separada, considera-se que a problematização e o desenvolvimento aconteceram paralelamente. Nessa etapa, os estudantes realizaram pesquisa individual e coletiva.

No trabalho 1, após a apresentação de uma linha do tempo sobre a aproximação entre as áreas da comunicação e educação envolvendo os principais 
autores do campo teórico, a professora convidou os estudantes a pesquisarem tais autores. $\mathrm{O}$ trabalho foi desenvolvido em pequenos grupos e posteriormente apresentado a todos os colegas.

No trabalho 2, seguindo um roteiro, os estudantes pesquisaram uma organização que desenvolvesse atividade educomunicativa para apresentá-la aos colegas. Da apresentação e do posterior debate surgiu a necessidade de acompanhar as atividades a serem implementadas na comunidade por meio de um estudo sistemático, de modo que as intervenções fossem efetivas.

\subsection{Etapa de aplicação}

Ao longo do processo, a professora propôs que os estudantes participassem ativamente da comunidade que os cercava, identificassem quais eram os conhecimentos nela presentes e quais problemas enfrentavam em suas atividades diárias. Da mesma forma que a professora buscava emancipar os estudantes em sala de aula, propiciava que eles repetissem esse cuidado na comunidade em que atuariam. O objetivo era mostrar aos estudantes, prestes a desenvolver atividades com a comunidade, a importância da atuação colaborativa.

Assim, com base em Peruzzo ${ }^{36}$, elegeu-se o principal pressuposto da disciplina: para fazer comunicação comunitária é importante a escuta ativa. A autora também propôs que é fundamental não fazer para a comunidade, mas fazer com a comunidade.

Após as cinco primeiras semanas da disciplina, a professora orientadora deixou os estudantes livres para que atuassem em uma única comunidade, tal como um bairro, ou para que cada equipe buscasse onde queria desenvolver a atividade. Tratava-se do processo de intervenção na realidade. No ano analisado, os estudantes optaram por atuar em diferentes comunidades.

Todo esse processo se construiu por meio de discussão e produção coletiva. Depois da primeira visita à comunidade, através da análise crítica e construtiva das realidades onde os projetos foram desenvolvidos, os estudantes passaram a ter encontros presenciais sob orientação da professora. Nesse momento presenciou-se a discussão coletiva, crítica e reflexiva dos membros das equipes. Esses encontros foram intitulados "reuniões de trabalho".

36. PERUZZO, Cicilia M. Krohling. Revisitando os conceitos de comunicação popular, alternativa e comunitária. In: CONGRESSO BRASILEIRO DE CIÊNCIAS DA COMUNICAČ̃̃O, 29. 2006, Brasília, DF. Anais.. Brasília, DF: Intercom, 2006 Disponível em: <http:// www.unifra.br/professores/ rosana/Cicilia\%2BPeruzzo \%2B.pdf>. Acesso em: 3 out. 2017.

\subsection{Etapa de avaliação}

A avaliação aconteceu ao longo da disciplina de forma gradual por meio de atividades individuais e em grupo. Buscou-se, nesse sentido, que os estudantes tivessem a capacidade de utilizar, aplicar, integrar e ressignificar saberes para voltar ao ponto de partida e responder às mesmas questões iniciais propostas pela professora. 
A produção coletiva foi construída por meio das seguintes atividades: busca por autores indicados pela professora para apresentação ao grupo; construção de um case sobre uma organização não governamental (ONG), instituição ou organização da sociedade civil de interesse público (OSCIP); exercícios realizados após a leitura de textos; mapeamento, diagnóstico e intervenção na comunidade; produção de um portfólio com as atividades desenvolvidas.

Os portfólios elaborados seguiram um guia-base, no entanto apresentaram-se de formas diferentes, pois cada equipe atendeu a uma comunidade e realizou atividades específicas relacionadas às realidades encontradas. Após a descrição das etapas adotadas por meio da metodologia de projetos na disciplina Mídia e Educação, observou-se que foi possível criar processos reflexivos que permitiram aos estudantes pesquisar, ir a campo, argumentar e defender suas ideias. O conhecimento desenvolvido tornou-se pertinente à medida que evidenciou:

- O contexto, por meio do problema trabalhado pelos estudantes nas comunidades distintas às quais se dirigiram. Este estava localizado e construído historicamente, conectado ao universo investigado. Os estudantes partiram de vivências e experiências trazidas pela própria comunidade.

- O global, que se refere às relações entre o todo e as partes, envolvendo a comunidade além do seu contexto. No todo organizacional do qual a comunidade fazia parte tinha-se o compromisso com o ambiente e a sociedade como eixo estrutural de toda atividade desenvolvida ao longo do semestre. O projeto permitiu que os estudantes entendessem sua participação social enquanto educomunicadores. As conclusões sobre as ações realizadas não se limitaram ao espaço no qual intervieram, mas também permitiram estabelecer generalizações sobre as ações realizadas, o que foi importante para a construção do conhecimento.

- O multidimensional, que envolve as unidades complexas do ser humano e da sociedade; revelado pelos vínculos do mundo real e dos problemas extraídos das realidades vivenciadas, ultrapassando interesses econômicos e se inserindo em diferentes dimensões (social, biológica, ambiental e outras).

- O complexo, presente em toda atividade na qual o professor contextualizava a disciplina e o que nela seria desenvolvido, e também durante o seu desenvolvimento. Quando a disciplina foi aceita como um objeto de ensino, fez-se possível aplicar o conhecimento sobre como se aprende para, então, determinar a metodologia em sua função social. Interessavam, nesse sentido, todas as habilidades individuais e grupais que se precisou desenvolver para alcançar a meta proposta. A possibilidade de relacionar os novos conteúdos ao conhecimento já existente permitiu soluções para os sistemas complexos com os quais os estudantes se depararam nas comunidades. 
comunicação \& educação • Ano XXIII • número 1 • jan/jun 2018

\section{CONSIDERAÇÕES FINAIS}

Nota-se que a atualidade demanda contínuas transições na atividade de qualquer profissional. Esta pesquisa alerta e abre novas possibilidades que exigem a quebra de barreiras para a aproximação das ciências, de forma a possibilitar também o pleno desenvolvimento do professor em sua atuação. Torna-se, assim, urgente a compreensão da transição que se vive em termos de economia, sociedade, organizações e indivíduos para que o professor, a partir de atividades que aliam comunicação e educação, favoreça um ensino efetivamente capaz de preparar os estudantes para lidar com sua própria realidade.

Não há um modelo único para se trabalhar com educomunicação nas comunidades, mas existem particularidades centrais que a caracterizam. Após este estudo, observa-se que ao fazer educomunicação pode-se encontrar uma pluralidade de formas de atuar na comunidade.

Nessa perspectiva, necessita-se de novos agentes e cenários educativos. O ensino precisa estar melhor associado à pesquisa para romper com o paradigma da repetição, incorporando processos metodológicos ativos pautados por questionamentos que abracem as inquietações de um contexto global.

Uma prática pedagógica condizente com a realidade da universidade e da sociedade, que agrega e transforma o conhecimento numa visão sistematizada, inovadora e holística, permite a superação de um ensino fragmentado. O docente deve estar aberto para favorecer que seus estudantes tenham múltiplas experiências, e estas precisam ser possibilitadas nas diferentes instituições educacionais para garantir o contato dos alunos com a sociedade. Atuar na comunidade como agente educativo valoriza a comunicação e justifica o exercício primeiro de qualquer profissão, especialmente da docência.

Verificou-se que a metodologia de projetos é adequada à aplicação em diferentes âmbitos do conhecimento, sendo possível direcioná-la ao desenvolvimento de atividades educomunicativas. Essa metodologia considera os processos pedagógicos de criação, colaboração, autonomia, respeito e responsabilidade, sendo seu objetivo maior educar para a vida e permitir uma verdadeira redefinição dos conteúdos e espaços educativos. Comunicação e educação são eternos processos, estão sempre inacabados e em fluxo, renovam-se e renascem a cada nova prática educomunicativa.

\section{REFERÊNCIAS BIBLIOGRÁFICAS}

BEHRENS, Marilda Aparecida. Projetos de aprendizagem colaborativa num paradigma emergente. In: MORAN, José Manuel; MASETTO, Marcos Tarciso; BEHRENS, Marilda Aparecida. Novas tecnologias e mediação pedagógica. Campinas: Papirus, 2000.

Paradigma da complexidade. Petrópolis: Vozes, 2008. 
BRASIL. Ministério da Educação. Secretaria de Educação Fundamental. Parâmetros Curriculares Nacionais: terceiro e quarto ciclos - apresentação dos temas transversais. Brasília, DF: MEC; SEF, 1998.

Conselho Nacional de Educação. Câmara de Educação Superior. Resolução CNE/CES noำ 1, de 27 de setembro de 2013. Institui as Diretrizes Curriculares Nacionais para o curso de graduação em Jornalismo, bacharelado, e dá outras providências. Diário Oficial da União, Brasília, DF, $1^{\circ}$ out. 2013. Seção 1, p. 26.

CITELLI, Adilson O.; COSTA, Maria Cristina C. (orgs.). Educomunicação: construindo uma nova área de conhecimento. São Paulo: Paulinas, 2011.

DEMO, Pedro. Desafios modernos da educação. Petrópolis: Vozes, 1995.

FREIRE, Paulo. Extensão ou comunicação? Rio de Janeiro: Paz e Terra, 1983.

. Pedagogia da autonomia: saberes necessários à prática educativa. São Paulo: Paz e Terra, 2003.

KAPLÚN, Mario. Comunicación entre grupos: el método del Cassete-Foro. Buenos Aires: Humanitas, 1988.

MORIN, Edgar. Os sete saberes necessários à educação do futuro. São Paulo: Cortez; Brasília, DF: Unesco, 2011.

PERUZZO, Cicilia M. Krohling. Revisitando os conceitos de comunicação popular, alternativa e comunitária. In: CONGRESSO BRASILEIRO DE CIÊNCIAS DA COMUNICAÇÃO, 29., 2006, Brasília, DF. Anais... Brasília, DF: Intercom, 2006. Disponível em: <http://www.unifra.br/professores/rosana/ Cicilia\%2BPeruzzo\%2B.pdf>. Acesso em: 3 out. 2017.

ROSEMBERG, Marshall B. Comunicação não violenta: técnicas para aprimorar relacionamentos pessoais e profissionais. São Paulo: Ágora, 2006.

SANTOS, Edmea. Pesquisa-formação na cibercultura. Santo Tirso: Whitebooks, 2014.

SOARES, Ismar de Oliveira. Educomunicação: conceito, o profissional, a aplicação. São Paulo: Paulinas, 2011.

SOUZA, Suyanne Tolentino. Ensino-aprendizagem na cibercultura: a mediação pedagógica na modalidade vídeo na educação superior. 2014. 291 f. Dissertação (Doutorado) - Pontifícia Universidade Católica do Paraná, Curitiba, 2014. Disponível em: <http://www.biblioteca.pucpr.br/tede/tde busca/arquivo.php?codArquivo=2960>. Acesso em: 1 jun. 2017.

ZABALA, Antoni. Enfoque globalizador e pensamento complexo: uma proposta para o currículo escolar. Porto Alegre: Artmed, 2002. 
